\title{
Research on grade evaluation of green urbanization based on cloud matter element model
}

\author{
Wei Jia ${ }^{1, a}$, Bing Liu ${ }^{1}$, Wei Ding ${ }^{2}$ and Hui Li $^{1}$ \\ ${ }^{1}$ College of Geomatics of Shandong University of Science and Technology, Qingdao 266590, China \\ ${ }^{2}$ College of Chemical Engineering of China University of Petroleum, Qingdao 266580, China
}

\begin{abstract}
In the important transition period of urbanization development in China, the concept of "green development" was integrated into the current urbanization research. This paper constructs the grade evaluation index system from six dimensions: population employment, economic development, urban construction, residents' life, social development and ecological development, and combines the cloud model with the matter element model to construct the green urbanization cloud element material model. We took Shandong Province as an example and evaluated the current level of green urbanization in 17 cities by using this model. The results showed that the green urbanization levels of the four cities such as Ji'nan and Qingdao are the highest; the green urbanization levels of the nine cities such as Zibo and Weifang are good; the green urbanization levels of the four cities such as Zaozhuang and Heze are low. Through analysis, the evaluation results of the green urbanization cloud element matter model are objective and accurate, which verifies the rationality of using this model to evaluate the level of green urbanization, and improved the theoretical research of the current green urbanization. In practice, we can provide scientific guidance for the future development of green urbanization in cities to promote the healthy development of China's green urbanization.
\end{abstract}

\section{Introduce}

Since the reform and opening up, the rapid development of economy and the rapid expansion of urban population had greatly promoted the process of urbanization in China. In the past 40 years, the urbanization rate in China has risen from the initial $20 \%$ to more than $50 \%$. By the end of 2017, the total number of cities in China had reached 657 , and the urbanization rate was as high as $57.4 \%$ [1]. However, with the development of social economy, China's urbanization is also facing a series of social issues such as the ecological environment, resource utilization, employment, land planning, urban transportation, food safety, population aging and so on [2]. In order to solve the above problems, the government is determined to promote the construction of green urbanization in China with the concept of sustainable development [3].

The research of green urbanization by foreign scholars began with the "green urbanism" [4]. Many scholars have shifted the focus of urbanization research from the study of single population or economic index to the comprehensive quality research of multi-dimensional and multi-perspective of urban development. In 1987, the Soviet scholar Yanitsky proposed to realize the recycling of the ecological environment in the urban development, and integrate green transportation and green construction into urban development. In the "Green City", Indian scholars have proposed that the development of green urbanization must be harmonized with environmental protection and the healthy development of people. In the domestic, the research of green urbanization is carried out with the introduction of ecological civilization and new urbanization [5-7]. In the 1980s, Ma Shijun proposed "Socio-Economic-Natural Compound Ecological Theory" and considered that urbanization research is a complex ecosystem. When researching green urbanization, Luo Yong pointed out that the development of green urbanization should include multiple aspects green economy, green social progress, improved ecological environment and construction of ecological cities; "National New Urbanization Planning (20142020)" proposes to transform the traditional urbanization development mode. We should develop a new type of urbanization that is coordinated development between man and nature. "Opinions on Accelerating the Construction of Ecological Civilization" was released in 2015, Government stated clearly that we should vigorously promote green urbanization.

However, the research of green urbanization in China is still at an exploratory stage [8-9]. Due to the lack of unified assessment index system and standards, the current research results are relatively few. At the same time, these studies are mainly qualitative research on the theoretical level of development model, countermeasures and suggestions, and lack of quantitative method of green urbanization evaluation research and empirical research. Based on this, the purpose of this study was is to build the evaluation index system for green urbanization by taking Shandong Province as an example, and conduct an objective and quantitative evaluation of the development

*Corresponding author: ${ }^{a} 575393478 @ q q . c o m$ 
level of green urbanization in the 17 cities by using the cloud matter element model. This study can theoretically improve the research of domestic green urbanization and improve the credibility of the green urbanization evaluation system. In practice, this method can provide guidelines for the government to formulate future green urbanization development.

\section{Construction of index system and evaluation methods}

\subsection{Constructing green urbanization evaluation index system}

Green urbanization should be a new urbanization model based on economics, environment, ecology, urban construction and many other disciplines, to realize the sustainable development of population, economy, resources and environment [10-11]. Therefore, through the integration of existing urbanization, green development, and circular economy index systems, this paper highlights the formulation of cross-cutting indexes for green development in economy, resources, environment, and society [12-13]. Based on 6 aspects of population employment, economic development, urban construction, residents' life, social development and ecological development, this paper selects 23 index layers to establish the green urbanization grade evaluation index system. Table 1 shows the evaluation index system of green urbanization grade.

The index data needed in this paper comes from "Shandong Statistical Yearbook" and "Shandong Provincial Urban Construction Statistical Yearbook". Some of the data are from "The Social Development Statistical Bulletins" of all cities in Shandong Province.

Table 1 Green urbanization grade evaluation index system

\begin{tabular}{|c|c|c|}
\hline Target layer & Criterion layer & Index layer \\
\hline \multirow{23}{*}{$\begin{array}{c}\text { Green } \\
\text { Urbanization } \\
\text { Grade }\end{array}$} & \multirow{3}{*}{$\begin{array}{c}\text { Population } \\
\text { employment } \\
C_{1} \\
\end{array}$} & Urbanization rate $(\%) C_{11}$ \\
\hline & & Proportion of employees (\%) $C_{12}$ \\
\hline & & Per capita GDP (¥) $C_{13}$ \\
\hline & \multirow{4}{*}{$\begin{array}{c}\text { Economic } \\
\text { development } \\
C_{2}\end{array}$} & Per capita local fiscal general income $(¥) C_{21}$ \\
\hline & & The proportion of tertiary industry in GDP $(\%) C_{22}$ \\
\hline & & Foreign-trade dependence (\%) $C_{23}$ \\
\hline & & Ten thousand yuan GDP energy consumption (tons of standard coal) $C_{24}$ \\
\hline & \multirow{5}{*}{$\begin{array}{c}\text { Urban } \\
\text { construction } \\
C_{3}\end{array}$} & Urban per capita road area $\left(\mathrm{m}^{2}\right) C_{31}$ \\
\hline & & The number of buses per 10,000 people $C_{32}$ \\
\hline & & Water usage rate $(\%) C_{33}$ \\
\hline & & Gas usage rate $(\%) C_{34}$ \\
\hline & & The proportion of built-up area to administrative area (\%) $C_{35}$ \\
\hline & \multirow{4}{*}{$\begin{array}{c}\text { Resident life } \\
C_{4}\end{array}$} & Urban per capita disposable income $(¥) \quad C_{41}$ \\
\hline & & Engel's Coefficient of urban residents (\%) $C_{42}$ \\
\hline & & Car ownership per 100 households $C_{43}$ \\
\hline & & Registered unemployment rate $(\%) C_{44}$ \\
\hline & \multirow{3}{*}{$\begin{array}{c}\text { Social } \\
\text { development } \\
C_{5} \\
\end{array}$} & The number of doctors per 10,000 people $C_{51}$ \\
\hline & & R\&D expenditure to GDP ratio (\%) $C_{52}$ \\
\hline & & The urban-rural income gap index $C_{53}$ \\
\hline & \multirow{4}{*}{$\begin{array}{c}\text { Ecological } \\
\text { development } \\
C_{6}\end{array}$} & Centralized treatment rate of sewage treatment plant $(\%) C_{61}$ \\
\hline & & Sulfur dioxide emission of 10,000 yuan GDP(kg/10,000 yuan) $C_{62}$ \\
\hline & & COD of 10,000 yuan GDP(kg/10,000 yuan) $C_{63}$ \\
\hline & & Per capita park green area $\left(\mathrm{m}^{2}\right) C_{64}$ \\
\hline
\end{tabular}

\subsection{Establishment evaluating model}

The matter-element analysis method was proposed by Cai Wen, and it has been applied to engineering science and technology [14]. The key part of this method is to take the certain and uncertain connections between the universal things as an integrated certain-uncertain system to analyse. Based on the matter-element theory, the constructed green urbanization matter element model is as follows:

$$
R=\left[\begin{array}{ccc}
N & C_{1} & V_{1} \\
& C_{2} & V_{2} \\
& \cdots & \cdots \\
& C_{n} & V_{n}
\end{array}\right]
$$

Where $N$ indicates the level of green urbanization, $C_{i}$ indicates the index that affects green urbanization, $V_{i}$ is the range of green urbanization level $N$ for $C_{i}$.

The cloud model was first proposed by Academician Li Deyi, this model can transform qualitative indicators into quantitative descriptions [15]. Since the cloud model was put forward, it has been successfully applied to natural language processing, data mining, decision analysis, intelligent control, and image processing. The "Normal cloud" is used in this paper, and it is generally expressed as $\left(E_{x}, E_{n}, H_{e}\right), E_{x}$ is the expected value of each evaluation index, that is, the target value; $E_{n}$ is the central value of the $\sigma$ value parameter for which each index value satisfies a normal distribution, also called "entropy"; $H_{e}$ is the $\sigma$ value of the normal distribution to which the "entropy" value obeys. 
This paper combines the cloud model with the matter element model to construct cloud matter element model. This model can make full use of the advantages of cloud model to transform the qualitative and quantitative factors, and improve the deficiency of traditional matter element models. The cloud matter element model is applied to the study of green urbanization for the first time. This model replaces the $V$ in the green urbanization matter element model with the normal cloud model $\left(E_{x}, E_{n}, H_{e}\right)$. The green urbanization cloud matter element model constructed is as follows:

$$
R_{\text {cloud }}=\left[\begin{array}{ccc}
N & C_{1} & \left(E_{x 1}, E_{n 1}, H_{e 1}\right) \\
& C_{2} & \left(E_{x 1}, E_{n 1}, H_{\mathrm{e} 2}\right) \\
\ldots & \ldots \\
& C_{n} & \left(E_{x n}, E_{n n}, H_{e n}\right)
\end{array}\right]
$$

Compared with existing methods for evaluating green urbanization, such as fuzzy mathematics, grey evaluation, and analytic hierarchy process, the cloud matter element model has the following advantages: The model can establish correlation function for the complex diversity of current green urbanization studies; The model can quantify each indicator to achieve the conversion between qualitative indicators and quantitative indicators to make the evaluation results more accurate. In summary, the use of this model for the evaluation of green urbanization grade can well reflect the objective level of the current development of green urbanization [16].

\section{Grade evaluation of green urbanization}

\subsection{Determine the index value and the boundaries of the evaluation index grade}

This paper divides the results of green urbanization grade evaluation into' excellent' 'good' 'general'.Through the results, we can directly see the current level of green urbanization in each city. This paper also needs to be based on the reference national standards and consult relevant experts to determine the index value and the boundaries of each evaluation index.

\subsection{Determine the index weights by the entropy method}

In order to ensure the objectivity of this study, this paper uses entropy weight method to determine the weight value of different evaluation indexes [17-18]. Specific steps are as follows: index

1) Standardized treatment of each green urbanization

$$
Y_{i j}=\frac{X_{i j}-\min \left(X_{j}\right)}{\min \left(X_{j}\right)-\max \left(X_{j}\right)}
$$

Where $X_{i j}$ indicates the index value of the ' $j-t h^{\prime}$ index of the ' $i$-th' city, $Y_{i j}$ is the result of standardized treatment, $\min \left(X_{j}\right)$ is the minimum value of the ' $j$-th' index, and $\max \left(X_{j}\right)$ is the maximum value of the ' $j$-th' index.

2) Calculate the entropy of each green urbanization index

$$
\begin{gathered}
P_{i j}=\frac{Y_{i j}}{\sum_{i=1}^{n} Y_{i j}} \\
E_{j}=-\ln (n)^{-1} \sum_{i=1}^{n} P_{i j} \ln P_{i j}
\end{gathered}
$$

Where $P_{i j}$ indicates the weight value of the ' $j$-t $h^{\prime}$ index of the ' $i-t h^{\prime}$ city, $E_{j}$ indicates the entropy of the ' $j$-th' index.

3) Calculate weight values of each green urbanization index by the entropy

$$
W_{j}=\frac{1-E_{j}}{j-\sum E_{j}}
$$

\begin{tabular}{|c|c|c|c|c|}
\hline $\begin{array}{l}\text { Target } \\
\text { layer }\end{array}$ & $\begin{array}{c}\text { Criterion } \\
\text { layer }\end{array}$ & Weight & $\begin{array}{l}\text { Index } \\
\text { layer }\end{array}$ & Weight \\
\hline \multirow{23}{*}{$\begin{array}{c}\text { Green } \\
\text { Urbaniza } \\
\text { tion } \\
\text { Grade }\end{array}$} & \multirow{3}{*}{$C_{1}$} & \multirow{3}{*}{0.113463} & $C_{11}$ & 0.046455 \\
\hline & & & $C_{12}$ & 0.038287 \\
\hline & & & $C_{13}$ & 0.028721 \\
\hline & \multirow{4}{*}{$C_{2}$} & \multirow{4}{*}{0.014242} & $C_{21}$ & 0.003244 \\
\hline & & & $C_{22}$ & 0.003815 \\
\hline & & & $C_{23}$ & 0.003849 \\
\hline & & & $C_{24}$ & 0.003334 \\
\hline & \multirow{5}{*}{$C_{3}$} & \multirow{5}{*}{0.295067} & $C_{31}$ & 0.055298 \\
\hline & & & $C_{32}$ & 0.037551 \\
\hline & & & $C_{33}$ & 0.088478 \\
\hline & & & $C_{34}$ & 0.080256 \\
\hline & & & $C_{35}$ & 0.033483 \\
\hline & \multirow{4}{*}{$C_{4}$} & \multirow{4}{*}{0.164543} & $C_{41}$ & 0.031543 \\
\hline & & & $C_{42}$ & 0.056158 \\
\hline & & & $C_{43}$ & 0.030241 \\
\hline & & & $C_{44}$ & 0.0466 \\
\hline & \multirow{3}{*}{$C_{5}$} & \multirow{3}{*}{0.308392} & $C_{51}$ & 0.082484 \\
\hline & & & $C_{52}$ & 0.075723 \\
\hline & & & $C_{53}$ & 0.150184 \\
\hline & \multirow{4}{*}{$C_{6}$} & \multirow{4}{*}{0.104294} & $C_{61}$ & 0.030877 \\
\hline & & & $C_{62}$ & 0.017481 \\
\hline & & & $C_{63}$ & 0.029642 \\
\hline & & & $C_{64}$ & 0.026294 \\
\hline
\end{tabular}

According to formula (4), we calculate the weight of each criterion layer $\omega_{i}$ and the weight of each index layer $\omega_{i j}$. The results are shown in Table 2.

Table 2 Green urbanization evaluation index weight

\subsection{Determine the grade boundary cloud model of green urbanization evaluation index}

In this paper, the index boundary used in grading evaluation of green urbanization is regarded as a doubleconstrained space $\left[C_{\min }, C_{\max }\right]$.Considering the 
uncertainty of the double-constrained spatial limit value and making appropriate changes to it, the conversion relationship between the interval and the cloud model is used to obtain $E_{x}$ and $E_{n}$.

$$
\begin{aligned}
E_{x} & =\frac{C_{\max }+C_{\min }}{2} \\
E_{x} & =\frac{C_{\max }-C_{\min }}{6} \\
H_{e} & =s
\end{aligned}
$$

Where $S$ is a constant, It can be adjusted according to the actual situation and experts' opinion.

The grade boundary cloud model of Shandong Province's green urbanization evaluation index can be obtained through calculation (Table 3 ). The three numbers of each item in the table represent the digital characteristics of the green urbanization cloud model $\left(E_{x}, E_{n}, H_{e}\right)$.

Table 3 The grade boundary cloud model

\begin{tabular}{|l|l|l|l|}
\hline Index & \multicolumn{1}{|c|}{ Excellent } & \multicolumn{1}{|c|}{ Good } & \multicolumn{1}{|c|}{ Genenral } \\
\hline$C_{11}$ & $(67,1.667,0.02)$ & $(55,2.333,0.1)$ & $(47.5,0.167,0.01)$ \\
\hline$C_{12}$ & $(77,1.333,0.01)$ & $(69.5,1.167,0.02)$ & $(63,1,0.1)$ \\
\hline$C_{13}$ & $(113885,16713.2,5)$ & $(51274,4157,5)$ & $(34353.5,1483.17,5)$ \\
\hline$C_{21}$ & $(10060,630.333,2)$ & $(6427.5,580.5,2)$ & $(3416,423.333,2)$ \\
\hline$C_{22}$ & $(53.5,1.833,0.01)$ & $(43.35,1.55,0.01)$ & $(36.35,0.783,0.01)$ \\
\hline$C_{23}$ & $(36.5,2.833,0.02)$ & $(22,2,0.01)$ & $(0.1,0.02,0.01)$ \\
\hline$C_{24}$ & $(0.1,0.02,0.01)$ & $(0.225,0.022,0.01)$ & $(0.375,0.028,0.01)$ \\
\hline$C_{31}$ & $(10,0.6,0.01)$ & $(7.25,0.317,0.01)$ & $(5,0.433,0.01)$ \\
\hline$C_{32}$ & $(15.65,1.117,0.02)$ & $(9.35,0.983,0.01)$ & $(5.35,0.35,0.01)$ \\
\hline$C_{33}$ & $(99.75,0.083,0.01)$ & $(98.75,0.25,0.01)$ & $(97.75,0.083,0.01)$ \\
\hline$C_{34}$ & $(99.75,0.083,0.01)$ & $(99,0.167,0.01)$ & $(98.25,0.083,0.01)$ \\
\hline$C_{35}$ & $(13.5,1.5,0.02)$ & $(7.5,0.5,0.01)$ & $(4.4,0.533,0.01)$ \\
\hline$C_{41}$ & $(38603.5,1664.83,5)$ & $(28443,1722,5)$ & $(22699.5,192.5,0.5)$ \\
\hline$C_{42}$ & $(24.4,0.3,0.01)$ & $(26.85,0.517,0.01)$ & $(29.8,0.4 .667,0.02)$ \\
\hline$C_{43}$ & $(72.9,2.967,0.02)$ & $(53.9,3.367,0.02)$ & $(32.95,3.617,0.02)$ \\
\hline$C_{44}$ & $(1.25,0.2,0.01)$ & $(2.1,0.283,0.01)$ & $(2.95,3.617,0.02)$ \\
\hline$C_{51}$ & $(82,5.5,0.02)$ & $(59.5,2,0.02)$ & $(51.5 .667,0.01)$ \\
\hline$C_{52}$ & $(3.25,0.417,0.01)$ & $(1.75,0.083,0.01)$ & $(1.25,0.083,0.01)$ \\
\hline$C_{53}$ & $(1.95,0.05,0.01)$ & $(2.25,0.05,0.01)$ & $(2.6,0.067,0.01)$ \\
\hline
\end{tabular}

\begin{tabular}{|l|l|l|l|}
\hline$C_{61}$ & $(96.7,0.167,0.01)$ & $(95.7,0.167,0.01)$ & $(94.6,0.2,0.01)$ \\
\hline$C_{62}$ & $(0.75,0.183,0.01)$ & $(2.6,0.433,0.01)$ & $(5.4,0.5,0.01)$ \\
\hline$C_{63}$ & $(0.4,0.033,0.01)$ & $(0.85,0.117,0.01)$ & $(1.6,0.133,0.01)$ \\
\hline$C_{64}$ & $(18,1.333,0.02)$ & $(11.5,0.833,0.01)$ & $(6.5,0.833,0.01)$ \\
\hline
\end{tabular}

\subsection{Determination of association degree}

Assume that $x_{i}$ is a definite value; $E_{n}$ is an expected value; $E_{n}^{\prime}$ is a normal random number generated by the mean $E_{n}$ and the standard deviation $H_{e}$. The formula for calculating the degree of association degree $k(x)$ of the index value $x$ belonging to the green urbanization cloud model is:

$$
k(x)=\exp \left[-\frac{\left(x_{i}-E_{x}\right)^{2}}{2 E_{n}^{\prime 2}}\right]
$$

\subsection{The calculation of comprehensive association degree and the determination of grade evaluation result}

1) Calculate the association degree of green urbanization grade for each criterion layer

$$
k_{j}\left(p_{i}\right)=\sum_{i=1}^{n} \omega_{i j} k_{j}\left(v_{i}\right)
$$

Where $k_{j}\left(p_{i}\right)$ is the degree of association of the $i$ criterion layer to the green urbanization grade $j ; k_{j}\left(v_{i}\right)$ is the association degree of the $v_{i}$ index layer corresponding to the $i$ criterion layer to the green urbanization grade $j ; \omega_{i j}$ is the weight of each index layer.

\begin{tabular}{|c|c|c|c|c|c|c|c|c|c|}
\hline \multirow{2}{*}{ City } & \multicolumn{3}{|c|}{$C_{1}$} & \multicolumn{3}{|c|}{$C_{2}$} & \multicolumn{3}{|c|}{$C_{3}$} \\
\hline & Excellent & Good & General & Excellent & Good & General & Excellent & Good & General \\
\hline Ji'nan & 0 & 0 & 0.0029 & 0.0033 & 0 & 0.0005 & 0.2179 & 0.2245 & 0.1734 \\
\hline Qingdao & 0 & 0 & 0.0141 & 0.0003 & 0 & 0.0033 & 0.1990 & 0.1853 & 0.1657 \\
\hline Zibo & 0.0001 & 0.0182 & 0.0004 & 0.0033 & 0.0019 & 0 & 0.1723 & 0.2660 & 0.2357 \\
\hline Zaozhuang & 0.0047 & 0.0261 & 0.0167 & 0.0033 & 0.0033 & 0.0071 & 0.1692 & 0.2478 & 0.2767 \\
\hline Dongying & 0.0358 & 0.0135 & 0.0005 & 0.0033 & 0.0033 & 0.0071 & 0.2232 & 0.2067 & 0.2300 \\
\hline Yantai & 0 & 0 & 0.0031 & 0.0033 & 0.0071 & 0.0069 & 0.2201 & 0.1957 & 0.1693 \\
\hline Weifang & 0 & 0 & 0.0191 & 0.0033 & 0.0035 & 0.0062 & 0.2196 & 0.2665 & 0.1930 \\
\hline Ji'ning & 0 & 0.0395 & 0.0203 & 0.0033 & 0.0070 & 0.0063 & 0.1984 & 0.2359 & 0.2003 \\
\hline Tai'an & 0 & 0 & 0.0069 & 0.0033 & 0.0033 & 0.0066 & 0.1991 & 0.2658 & 0.1990 \\
\hline Weihai & 0.0002 & 0.0040 & 0.0014 & 0.0068 & 0.0033 & 0.0064 & 0.2232 & 0.2481 & 0.1797 \\
\hline Rizhao & 0 & 0.0002 & 0.0139 & 0.0033 & 0.0039 & 0.0063 & 0.1736 & 0.2329 & 0.2825 \\
\hline Laiwu & 0 & 0 & 0.0029 & 0.0033 & 0.0038 & 0.0052 & 0.1813 & 0.2590 & 0.2399 \\
\hline Linyi & 0 & 0.0398 & 0.0141 & 0.0033 & 0.0033 & 0.0060 & 0.2231 & 0.2646 & 0.1863 \\
\hline Dezhou & 0 & 0.0012 & 0.0478 & 0.0033 & 0.0039 & 0.0066 & 0.1954 & 0.2450 & 0.2256 \\
\hline Liaocheng & 0 & 0.0096 & 0.0457 & 0.0033 & 0.0033 & 0.0071 & 0.1701 & 0.2450 & 0.2496 \\
\hline Binzhou & 0 & 0 & 0.0132 & 0.0033 & 0.0045 & 0.0034 & 0.2252 & 0.2086 & 0.2020 \\
\hline Heze & 0 & 0 & 0.0466 & 0.0033 & 0.0033 & 0.0085 & 0.1685 & 0.2191 & 0.2812 \\
\hline
\end{tabular}

We finally obtain the association degree of each criterion layer corresponding to the green urbanization grade of each city in Shandong Province. (See Table 4)

Table 4 Grade association degree of evaluation criterion layer 
Continued Table 4

\begin{tabular}{|l|l|l|l|l|l|l|l|l|l|}
\hline \multirow{2}{*}{ City } & \multicolumn{3}{|c|}{$\boldsymbol{C}_{\mathbf{4}}$} & \multicolumn{3}{c|}{$\boldsymbol{C}_{\mathbf{5}}$} & \multicolumn{3}{c|}{$\boldsymbol{C}_{\mathbf{6}}$} \\
\cline { 2 - 10 } & Excellent & Good & General & Excellent & Good & General & Excellent & Good & General \\
\hline Ji'nan & 0.1019 & 0.0667 & 0.0027 & 0.2251 & 0.2250 & 0.2249 & 0.0779 & 0.0725 & 0.0697 \\
\hline Qingdao & 0.0595 & 0.0599 & 0.0868 & 0.2182 & 0.2241 & 0.2227 & 0.0777 & 0.0707 & 0.0594 \\
\hline Zibo & 0.0990 & 0.0867 & 0.0082 & 0.2134 & 0.2259 & 0.2258 & 0.0754 & 0.1012 & 0.0710 \\
\hline Zaozhuang & 0.0454 & 0.0664 & 0.0624 & 0.2156 & 0.2458 & 0.2258 & 0.0778 & 0.0778 & 0.0875 \\
\hline Dongying & 0.1004 & 0.0607 & 0.0072 & 0.2156 & 0.2259 & 0.2259 & 0.0998 & 0.0779 & 0.0610 \\
\hline Yantai & 0.0495 & 0.0780 & 0.0770 & 0.2258 & 0.2253 & 0.2258 & 0.0778 & 0.0776 & 0.0607 \\
\hline Weifang & 0.0985 & 0.0582 & 0.0473 & 0.2076 & 0.2259 & 0.2254 & 0.0773 & 0.0976 & 0.0635 \\
\hline Ji'ning & 0.0489 & 0.0589 & 0.0959 & 0.2091 & 0.2259 & 0.2257 & 0.0764 & 0.0981 & 0.0646 \\
\hline Tai'an & 0.0962 & 0.0969 & 0.0241 & 0.2105 & 0.2257 & 0.2258 & 0.0771 & 0.0979 & 0.0606 \\
\hline Weihai & 0.0624 & 0.0649 & 0.0561 & 0.2089 & 0.2259 & 0.2246 & 0.0986 & 0.0779 & 0.0601 \\
\hline Rizhao & 0.0651 & 0.0688 & 0.0566 & 0.2244 & 0.2257 & 0.2471 & 0.0770 & 0.0779 & 0.0614 \\
\hline Laiwu & 0.0984 & 0.0881 & 0.0273 & 0.2257 & 0.2263 & 0.2249 & 0.0700 & 0.0848 & 0.0780 \\
\hline Linyi & 0.0856 & 0.1025 & 0.0271 & 0.2083 & 0.2259 & 0.2761 & 0.0860 & 0.0630 & 0.0639 \\
\hline Dezhou & 0.0847 & 0.0603 & 0.0765 & 0.2045 & 0.2258 & 0.2760 & 0.0831 & 0.0771 & 0.0622 \\
\hline Liaocheng & 0.0587 & 0.0525 & 0.0909 & 0.2096 & 0.2259 & 0.3038 & 0.0765 & 0.0805 & 0.0690 \\
\hline Binzhou & 0.0566 & 0.0881 & 0.0456 & 0.2082 & 0.2259 & 0.2258 & 0.0699 & 0.0629 & 0.0735 \\
\hline Heze & 0.0585 & 0.0596 & 0.0963 & 0.2045 & 0.2758 & 0.2258 & 0.0764 & 0.0774 & 0.0698 \\
\hline
\end{tabular}

2) Calculate the association degree of green urbanization grade for target layer

$$
k_{j}(p)=\sum_{i=1}^{6} \omega_{i} k_{j}\left(p_{i}\right)
$$

Where $k_{j}(p)$ is the degree of association of the target layer corresponding to the green urbanization grades $j$.Where $\omega_{i}$ is the weight of each criterion layer.

We finally obtain the association degree of each target layer corresponding to the green urbanization grade. (See Table 5)

Table 5 Comprehensive association degree

\begin{tabular}{|l|l|l|l|}
\hline City & Excellent & Good & General \\
\hline Ji'nan & 0.1587 & 0.1542 & 0.1286 \\
\hline Qingdao & 0.1439 & 0.1410 & 0.1397 \\
\hline Zibo & 0.1409 & 0.1751 & 0.1480 \\
\hline Zaozhuang & 0.1414 & 0.171 & 0.1727 \\
\hline Dongying & 0.1634 & 0.1503 & 0.1452 \\
\hline Yantai & 0.1509 & 0.1483 & 0.139 \\
\hline Weifang & 0.1531 & 0.1681 & 0.1431 \\
\hline Ji'ning & 0.1391 & 0.1638 & 0.1536 \\
\hline Tai'an & 0.1476 & 0.1742 & 0.1395 \\
\hline Weihai & 0.1510 & 0.1622 & 0.1380 \\
\hline Rizhao & 0.1392 & 0.1578 & 0.1769 \\
\hline Laiwu & 0.1466 & 0.1696 & 0.1532 \\
\hline Linyi & 0.1532 & 0.1757 & 0.1529 \\
\hline Dezhou & 0.1434 & 0.1601 & 0.1763 \\
\hline Liaocheng & 0.1325 & 0.1601 & 0.1948 \\
\hline Binzhou & 0.1473 & 0.1523 & 0.146 \\
\hline Heze & 0.1304 & 0.1676 & 0.1811 \\
\hline
\end{tabular}

According to the principle of maximum association degree. The $j$ corresponding to $k_{j}(p)$ with the highest degree of correlation calculated from formula (10) is the green urbanization grade of each city in Shandong Province as evaluated. The results are shown in Table 6.

Table 6 Grade evaluation results of green Urbanization

\begin{tabular}{|l|l|}
\hline Grade & \multicolumn{1}{|c|}{ City } \\
\hline Excellent & Ji'nan Qingdao Dongying Yantai \\
\hline Good & Zibo Weifang Ji'ning Tai'an \\
\hline
\end{tabular}

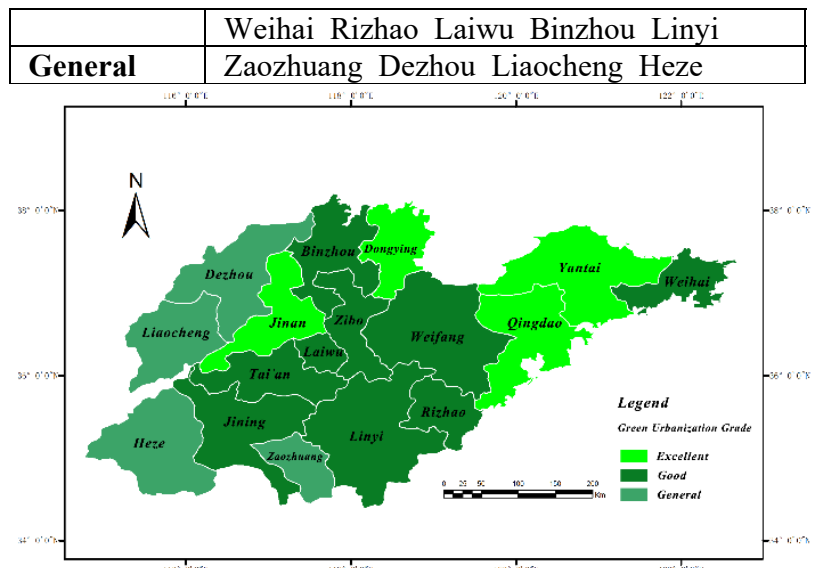

Figure 1 Grade map of green urbanization in Shandong

\section{Evaluation result analysis}

\subsection{Analysis of comprehensive association degree}

It can be seen from the evaluation results of the comprehensive association degree:

1) In the grade evaluation results of green urbanization in Shandong Province, Ji'nan, Qingdao, Dongying, Yantai have the highest degree of association with the grade 'excellent', which indicates that these cities have the highest level of green urbanization. These cities are the main parts of Shandong's two national strategies: "Shandong Peninsula Blue Economic Zone" and "Yellow River Delta Efficient Ecological Economic Zone". While developing the Blue Economy and efficient ecological economy, it will play an indirect role in promoting the development of green urbanization. Therefore, the level of green urbanization in these cities is obviously better than that in other cities.

2) Zibo, Weifang, Ji'ning, Tai'an, Linyi, Weihai, Rizhao, Laiwu and Binzhou have the highest degree of correlation with the grade' good', which indicates that these cities have better levels of green urbanization. 
Among them, Weihai, Rizhao, and Weifang are coastal cities. These cities have better afforestation and environmental quality, and they have innate geographical advantages for advancing the process of green urbanization. Other cities are located in the central region of Shandong Province, and the overall level of development is relatively backward. However, it is possible to promote the level of green urbanization by highlighting urban features, strengthening ecological construction, and developing county-level economy.

3) Zaozhuang, Dezhou, Liaocheng, and Heze have the highest degree of association with the grade'general' . This shows that these cities have low levels of green urbanization. These cities are mainly located in the Southern and Western parts of Shandong province. For a long time, the economic development is relatively backward, the industrial structure is relatively single, and the proportion of the second industries is too high. Which lead to a low level of green urbanization in these cities.

\subsection{Analysis of association degree of criterion level}

From the evaluation results of each criterion level, it can be seen intuitively that each city has problems in the current development process of green urbanization. In terms of employment of the population, only Dongying is 'excellent' . Other cities should improve the employment environment, increase employment, and promote more people to settle in cities so as to drive the development of the city ; In terms of economic development, Ji'nan and Zibo are 'excellent', Other cities should make full use of their own advantages, optimize the industrial structure, develop characteristic industries, promote the development of a green economy, and strengthen regional economic exchanges; In terms of urban construction, Qingdao, Yantai and Binzhou are 'excellent'. Other cities should adjust the land structure, optimize the urban layout, improve the urban infrastructure, and increase land utilization; In terms of social development, Tai'an, Rizhao, Linyi, Dezhou, and Liaocheng are 'general' . These cities should actively improve the level of local education and medical care, promote the coordinated development of urban and rural integration, narrow the gap between urban and rural areas, and allow residents to share the fruits of economic development; In terms of ecological development, Zaozhuang and Dongying are 'general'. These cities should strengthen the treatment of environmental pollution, optimize the traditional industrial structure, develop the green recycling economy, and improve the urban ecological environment.

\section{Conclusions}

Through the analysis of the evaluation results of current green urbanization in Shandong Province, the following conclusions have been drawn:

1) The development level of green urbanization in eastern coastal cities of Shandong Province is obviously better than the others of Western and Southern Shandong; The green urbanization level of cities with superior geographical location, convenient transportation and abundant natural resources is better than other cities; The level of green urbanization in Ji'nan, Qingdao and surrounding radiating cities are better than other cities.

2) The green urbanization level of Ji'nan, Qingdao, Dongying and Yantai four cities are significantly better than other cities due to their superior geographical location, active policy support, good economic foundation, and abundant natural resources.

3) The green urbanization level of Zaozhuang, Dezhou, Liaocheng and Heze four cities are lower than other cities due to the lack of resources and the poor urban development foundation.

This paper studied current urbanization issues from the perspectives of people-oriented and green development. This paper constructs a green urbanization grade evaluation cloud matter element model by combining the cloud model with the matter element theory. Which is a preliminary exploration of the quantitative analysis and objective research of the current green urbanization. At the same time, this paper scientifically selects six dimensions of population employment, economic development, urban construction, residential life, social development, and ecological development to build green urbanization rating evaluation index system. On the basis of reflecting the current development level of green urbanization, it can further reflect the interaction mechanism of internal factors of green urbanization. By using the entropy method to calculate the weight of each index, it can effectively reduce the influence of subjective factors in the process of studying green urbanization problems, make the weight results more reasonable, and ensure the objectivity of the green urbanization rating evaluation results. Through analysis, it is found that the evaluation results of green urbanization grades in Shandong province obtained by using the cloud matter element model are basically consistent with the current levels of green urbanization in cities of Shandong province, which shows that the model is suitable for the evaluation of the development level of green urbanization. The model can intuitively compare the comprehensive level of green urbanization of each city in Shandong province by evaluation results of the comprehensive association degree. By analysing the evaluation results of each criterion level, we can accurately point out the advantages and disadvantages of each city in the current green development, and provide objective and effective decision-making basis for the green urbanization of the cities in the future. Compared with the existing green urbanization evaluation method, this method has strong operational and practical value.

\section{References}

1. C.L. Fang, The urbanization and urban development in China after the reform and opening-up [J], Economic Geography, 29, 19-25 (2009)

2. D.Y. Hong, Research on the resources and environmental problems in the process of green 
urbanization [J], Environmental Protection, 42, 1923(2014)

3. R.T. Zhang, H.F. Jiao, A review on new urbanization research in China [J], World Regional Studies, 25, 59-66 (2016)

4. B. Pandey, K. C. Seto, Urbanization and agricultural land loss in India: Comparing satellite estimates with census data $[\mathrm{J}]$, Journal of Environmental Management, $148,(2015)$

5. Z.Y. Ou Yang, J.J. Zhao, Z.H. Gui, Evaluation of Green Development in Cities of China [J], China Population Resources and Environment, 05, 11-15 (2009)

6. D.S. Xue, X.J. Zeng, Evaluation of China's urbanization quality and analysis of its spatial pattern transformation based on the modern life index [J], Acta Geographica Sinica, 71, 194-204(2016)

7. C.L. Fang, D.L. Wang, Comprehensive mearsures and improvement of Chinese urbanization development quality [J], Geographical Research, 30, 1931-1946(2011)

8. H.J. Su, B.N. Zhu, S.G. Li, Progress and prospection for the researches on evaluating China's urbanization quality [J]. Urban Problems, 12, 26-31 (2015)

9. Z.F. Dong, C.Y. Yang, Q. Wu, L. Gao, Study on the strategic framework of Chinese new green urbanization $[\mathrm{J}]$, Ecological Economy, 30, 7982(2014)

10. X.X. Li, Y.M. Liu, T. Song, Calculation of the Green Development Index [J], Social Sciences in China, 06, 69-95(2014)
11. X.H. Yi, J.H. Cheng, J. Chen, A Summary of Researches on Ecological Civilization Evaluation Index System [J], Statistics \& Decision, 18, 3236(2013)

12. H.Y. Mao, The research about an indictor system of sustainable develop in Shandong Province [J], Geographical Research, 04, 16-23(1996)

13. Q.J. Du, Q. Wu, Study on the Index System of Regional Urbanization Level [J], Urban Studies, 05, 5-8(2006)

14. Wen Cai, C.Y. Yang, Basic theory and methodology on Extenics [J], Chinese Science Bulletin, 58, 11901199(2013)

15. D.Y. Li, C.Y. Liu, Study on the Universality of the Normal Cloud Model [J], Engineering Science, 08, 28-34(2004)

16. Y.B. Guo, H.K. Wei, A review of literature on urbanization quality evaluation $[\mathrm{J}]$, Journal of Graduate School of Chinese Academy of Social Sciences, 02, 37-43(2013)

17. Y.M. Ma, Y.M. Wu, B.J. Wu, Comprehensive Evaluation of Sustainable Urban Development of Yangtze River Delta Based on Entropy Method[J],Economic Geography, 35, 47-53(2013)

18. F.X. Wang, A.H. Mao, H.L. Li, M.L. Jia, Quality Measurement and Regional Difference of Urbanization in Shandong Province Based on the Entropy Method [J], Scientia Geographica Sinica, 33, 1323-1329(2013) 